Archived version from NCDOCKS Institutional Repository http://libres.uncg.edu/ir/asu/

\title{
Appalachľan
}

$\overline{\text { B O O N E, N O R T H C A R O L I N A }}$

\section{Mechanical Ventilation-induced Diaphragmatic Atrophy Is Associated with Oxidative Injury and Increased Proteolytic Activity}

\author{
Authors: \\ R. Andrew Shanely, Murat A. Zergeroglu, Shannon L. Lennon, Takao Sugiura, Tossaporn \\ Yimlamai, Debbie Enns, Angelo Belcastro, and Scott K. Powers
}

\begin{abstract}
Prolonged mechanical ventilation (MV) results in reduced diaphrag-matic maximal force production and diaphragmatic atrophy. To investigate the mechanisms responsible for MV-induced diaphrag-matic atrophy, we tested the hypothesis that controlled MV results in oxidation of diaphragmatic proteins and increased diaphrag-matic proteolysis due to elevated protease activity. Further, we postulated that MV would result in atrophy of all diaphragmatic muscle fiber types. Mechanically ventilated animals were anesthe-tized, tracheostomized, and ventilated with $21 \% \mathrm{O} 2$ for 18 hours. MV resulted in a decrease ( $\mathrm{p} \nabla$ 0.05) in diaphragmatic myofibrillar protein and the cross-sectional area of all muscle fiber types (i.e., I, $\mathrm{IIa}, \mathrm{IId} / \mathrm{x}$, and IIb). Further, MV promoted an increase ( $\mathrm{p} \otimes 0.05)$ in diaphragmatic protein degradation along with elevated ( $\mathrm{p} \otimes 0.05)$ calpain and $20 \mathrm{~S}$ proteasome activity. Finally, MV was also associated with a rise $(\mathrm{p} \otimes 0.05)$ in both protein oxidation and lipid peroxidation. These data support the hypothesis that

MV is associated with atrophy of all diaphragmatic fiber types, increased diaphragmatic protease activity, and augmented diaphragmatic ox-idative stress.
\end{abstract}

R. Andrew Shanely, Murat A. Zergeroglu, Shannon L. Lennon, Takao Sugiura, Tossaporn Yimlamai, Debbie Enns, Angelo Belcastro, and Scott K. Powers (2002) "Mechanical Ventilation-induced Diaphragmatic Atrophy Is Associated with Oxidative Injury and Increased Proteolytic Activity" Version of Record Available @ American Journal Of Respiratory And Critical Care Medicine Vol 166 Version of Record Available @ (DOI: 10.1164/rccm.200202-088OC) 


\title{
Mechanical Ventilation-induced Diaphragmatic Atrophy Is Associated with Oxidative Injury and Increased Proteolytic Activity
}

\author{
R. Andrew Shanely, Murat A. Zergeroglu, Shannon L. Lennon, Takao Sugiura, Tossaporn Yimlamai, \\ Debbie Enns, Angelo Belcastro, and Scott K. Powers \\ Department of Exercise and Sport Sciences and Department of Physiology, Center for Exercise Science, University of Florida, Gainesville, Florida; \\ Faculty of Medicine, Department of Sports Medicine, Ankara University, Ankara, Turkey; Laboratory of Biomechanics and Physiology, \\ Faculty of Liberal Arts, Yamaguchi University, Yamaguchi, Japan; and School of Kinesiology, Faculty of Health Sciences, University of Western \\ Ontario, London, Ontario, Canada
}

Prolonged mechanical ventilation (MV) results in reduced diaphragmatic maximal force production and diaphragmatic atrophy. investigate the mechanisms responsible for MV-induced diaphragmatic atrophy, we tested the hypothesis that controlled MV results in oxidation of diaphragmatic proteins and increased diaphragmatic proteolysis due to elevated protease activity. Further, we postulated that $\mathrm{MV}$ would result in atrophy of all diaphragmatic muscle fiber types. Mechanically ventilated animals were anesthetized, tracheostomized, and ventilated with $21 \% \mathrm{O}_{2}$ for 18 hours. $\mathrm{MV}$ resulted in a decrease $(\mathrm{p}<0.05)$ in diaphragmatic myofibrillar protein and the cross-sectional area of all muscle fiber types (i.e., $\mathrm{I}$, Ila, Ild/x, and IIb). Further, MV promoted an increase $(p<0.05)$ in diaphragmatic protein degradation along with elevated $(p<$

$0.05)$ calpain and $20 \mathrm{~S}$ proteasome activity. Finally, MV was also associated with a rise $(p<0.05)$ in both protein oxidation and lipid peroxidation. These data support the hypothesis that MV is associated with atrophy of all diaphragmatic fiber types, increased diaphragmatic protease activity, and augmented diaphragmaticoxidative stress.

Keywords: myosin heavy chain; oxidative stress; protein degradation; weaning

Mechanical ventilation (MV) provides a means of supporting blood gas homeostasis for patients who cannot maintain adequate alveolar ventilation. Unfortunately, prolonged MV (i.e., 3 days or more) is not without consequence because as many as $20 \%$ of patients experience difficulty in "weaning" from the ventilator (1). Although the underlying causes for weaning difficulties are not completely clear, respiratory muscle weakness due to atrophy and contractile dysfunction are potential mechanisms (2).

To date, only a few studies have investigated respiratory muscle function after controlled MV. In this regard, Le Bourdelles and coworkers (3) examined the effects of 48 hours of controlled MV on both atrophy and contractile properties in the rat diaphragm. The authors reported a significant reduction in isometric force generation and a decrease in both diaphragmatic mass (i.e., atrophy) and protein content (3).
Further, experiments performed in our laboratory have confirmed that as few as 18 hours of MV results in diaphragmatic contractile dysfunction (4) and atrophy (our unpublished observations). The mechanism(s) responsible for this atrophy are unknown and are the focus of the experiments described in this article.

Experiments investigating disuse locomotor skeletal muscle atrophy (e.g., hindlimb unloading) indicate that whereas all muscle fibers atrophy during prolonged periods of unloading, slow (i.e., Type I) muscle fibers are particularly susceptible to this type of atrophy (reviewed by Roy and coworkers [5]). In contrast, diaphragmatic inactivity induced by either unilateral denervation or tetrodotoxin blockade of nerve impulses results in atrophy of Type IIx and IIb fibers and hypertrophy of Type I and IIa fibers (6-8). At present, it is unclear which diaphragmatic fiber types are subject to atrophy during MV. It is also well known that locomotor muscle atrophy due to reduced use is associated with an increase in both oxidative stress (9) and protease-mediated protein degradation (10). In contrast, it is unknown whether prolonged MV results in increased protease activity and elevated protein degradation. Further, it is also unclear whether MV is associated with oxidative injury in the diaphragm. Therefore, on the basis of several voids in knowledge about the cellular effects of MV on the diaphragm, these experiments were designed to address the following questions.

\section{Question 1}

Which diaphragmatic fiber types are subject to atrophy during MV? To address this question, immunohistochemical procedures were used to identify diaphragmatic fiber types and computerized image analysis was employed to determine the effect of MV on muscle fiber cross-sectional area. On the basis of preliminary data in our laboratory, we hypothesized that short-term controlled MV induces atrophy of all four muscle fiber types in the diaphragm.

\section{Questlon 2}

Which proteolytic pathways are activated during MV? Two differing but complementary approaches were used to probe the activation of specific proteolytic pathways. First, we investigated the effects of specific calpain and proteasome inhibitors on the rates of protein breakdown in diaphragmatic strips in vitro. Further, we measured diaphragmatic calpain and proteasome activities. On the basis of preliminary experiments, we postulated that controlled MV increases diaphragmatic proteolysis by elevating both calpain and proteasome activities.

\section{Questlon 3}

Does MV result in oxidative injury in the diaphragm? This is an important question relative to diaphragmatic atrophy because 
oxidized proteins are associated with increased proteolysis (1114). Therefore, tissue levels of protein carbonyls and 8-isoprostane were measured to determine whether MV results in diaphragmatic protein oxidation and lipid peroxidation, respectively. On the basis of preliminary data, we hypothesized that controlled MV increases oxidative stress in the diaphragm.

\section{METHODS}

\section{AnImals and Experimental Design}

These experiments were approved by the University of Florida Animal Use Committee. Adult female Sprague-Dawley rats were randomly assigned to the following groups: (1) 18 hours of mechanical ventilation (MV) ( $\mathrm{n}=16),(2)$ control (CON) (acute anesthesia, no MV; $\mathrm{n}=16$ ), and (3) spontaneous breathing (SB) (anesthetized and spontaneously breathing for 18 hours; $\mathrm{n}=6$ ).

\section{Mechanical Ventllation Protocol}

Surgical procedures were performed using aseptic technique. After reaching a surgical plane of anesthesia (sodium pentobarbital, $50 \mathrm{mg} /$ $\mathrm{kg}$ body weight, intraperitoneal), animals were tracheostomized and mechanically ventilated (control mode) using a volume-driven ventilator (Columbus Instruments, Columbus, $\mathrm{OH}$ ). The tidal volume was about $1 \mathrm{ml} / 100 \mathrm{~g}$ of body weight, with a respiratory rate of 80 breaths/ minute, and a positive end-expiratory pressure (PEEP) of $1 \mathrm{~cm} \mathrm{H}_{2} \mathrm{O}$.

The carotid artery was cannulated for measurement of arterial blood pressure, $\mathrm{pH}$, and blood gases. A total of three arterial blood samples (about $100 \mu \mathrm{l} / \mathrm{sample)}$ were removed from animals at 5- to 6-hour intervals to determine arterial $\mathrm{pH}$ and blood gas tensions, using an electronic blood gas analyzer (Model 1610; Instrumentation Laboratory, Lexington, MA). The jugular vein was also cannulated for the infusion of saline and sodium pentobarbital (about $10 \mathrm{mg} / \mathrm{kg}$ body weight per hour). Body temperature was maintained at about $37 \pm$ $1^{\circ} \mathrm{C}$. Heart rate was monitored via a lead II electrocardiograph.

Continuing care during the experiment (both MV and SB animals) included expressing the bladder, removing airway mucus, lubricating the eyes, rotating the animal, passive movement of the limbs, and enteral nutrition. After 18 hours of mechanical ventilation, the diaphragm was removed, rapidly dissected, frozen, and stored at $-80^{\circ} \mathrm{C}$.

\section{Protocol for Control Anlmals}

Control animals were free of intervention and were anesthetized (sodium pentobarbital, about $50 \mathrm{mg} / \mathrm{kg}$, intraperitoneal). After reaching a surgical plane of anesthesia, the diaphragm was removed, dissected, frozen, and stored at $-80^{\circ} \mathrm{C}$.

\section{Spontaneous Breathing Protocol}

Animals were anesthetized (sodium pentobarbital, about $50 \mathrm{mg} / \mathrm{kg}$, intraperitoneal) and a surgical plane of anesthesia was maintained with sodium pentobarbital (about $10 \mathrm{mg} / \mathrm{kg}$ every hour, intravenous). These animals were not mechanically ventilated and breathed spontaneously during this time. Spontaneously breathing animals received continuing care and enteral nutrition as described for the MV animals. After 18 hours of spontaneous breathing, the diaphragm was removed, dissected, frozen, and stored at $-80^{\circ} \mathrm{C}$.

\section{TIssue Analysls}

All morphometric (histochemical) and biochemical assays were conducted on the costal region of the diaphragm. Specifically, diaphragm samples were removed from the entire midcostal muscle spanning from the costal margin to the central tendon. Samples used for morphometric analysis were frozen (liquid nitrogen) at an unstressed length (15) and stored at $-80^{\circ} \mathrm{C}$. Immunohistochemistry was performed to identify muscle fiber types and fiber cross-sectional area (CSA) was determined by computerized image analysis. Also, diaphragmatic myofibrillar protein concentration and total content were measured $(16,17)$ along with diaphragmatic water content.

As a marker of total in vitro protein degradation, the rate of tyrosine release from isolated diaphragm strips (about $40 \mathrm{mg} / \mathrm{strip}$ ) was measured with and without specific proteolytic inhibitors $(18,19)$. Nonlysosomal and noncalpain proteolysis (i.e., ubiquitin-proteasome system) was measured in the presence of the lysosomal and calpain inhibitor E-64d (Sigma, St. Louis, MO) $(20,21)$. Further, lysosomal and calpain proteolysis was measured in the presence of the proteasome inhibitor lactacystin (Boston Biochem, Boston, MA) (22, 23). Total calpain-like activity $(24,25)$ and activity of the $20 \mathrm{~S}$ proteasome (26) were also determined in diaphragm samples.

Levels of lipid peroxidation (8-isoprostane) (ELISA; Cayman Chemical, Ann Arbor, MI) and protein oxidation (protein carbonyl content) (27) were measured to determine oxidative damage in the diaphragm.

Comparisons between groups were made by a one-way analysis of variance and a Tukey test was used post hoc.

\section{RESULTS}

\section{Systemlc and Blologlc Response to Mechanlcal Ventllation}

Because hypoxia, hypercapnia, and respiratory acidosis are known to induce diaphragmatic dysfunction, we monitored arterial blood pressures, $\mathrm{pH}$, and the partial pressures of both $\mathrm{CO}_{2}$ and $\mathrm{O}_{2}$ during the 18 hours of $\mathrm{MV}$ in all MV animals. Arterial blood pressure and blood gas/pH homeostasis were well maintained during the period of MV. For example, arterial $\mathrm{Po}_{2}$ ranged from 95 to $79 \mathrm{~mm} \mathrm{Hg}$, whereas arterial $\mathrm{pH}$ varied from 7.42 to 7.47 during the 18 hours of mechanical ventilation.

Sepsis is associated with diaphragmatic contractile dysfunction; therefore, aseptic techniques were used throughout the MV experiments. Our observations indicate that the animals did not develop infections during MV. Microscopic examination of blood at the conclusion of MV revealed no detectable bacteria and postmortem examination of the lungs (histological) and peritoneal cavity (visual) revealed no abnormalities. Finally, we did not observe a significant decrease in total body mass or locomotor muscle mass after prolonged MV (Table 1). This is an important observation because sepsis is associated with rapid decreases in both body and locomotor muscle mass. Collectively, these observations indicate that our animals did not develop sepsis during MV.

\section{Body Welght and Dlaphragmatlc Atrophy}

Table 1 contains mean values ( \pm SEM) for body weight, diaphragm mass, as well as soleus mass obtained from both control and mechanically ventilated animals. Note that 18 hours of MV resulted in a significant decrease $(\mathrm{p}<0.05)$ in both total and costal diaphragmatic mass. Although crural diaphragmatic mass tended to be lower in MV animals compared with control animals, this difference did not reach significance $(p=0.12)$. As mentioned above, MV did not result in a loss of body mass or decrease soleus muscle mass (Table 1). These observations indicate that the mechanically ventilated animals received adequate nutrition and that the observed skeletal muscle atrophy was unique to the diaphragm.

\section{Flber CSA}

Immunohistochemical analysis revealed that fiber CSA did not differ in any fiber type between the control and spontaneously breathing animals. This indicates that exposure to 18 hours of sodium pentobarbital anesthesia does not result in diaphragmatic atrophy. In contrast, compared with control animals, 18 hours of MV induces significant myofiber atrophy as the CSA of all four fiber types was reduced $(\mathrm{p}<0.05)$ by MV (Figure 1$)$. Interestingly, the Type II fibers atrophied to a greater extent than the Type I fibers, -24 to $-30 \%$ versus $-15 \%$, respectively. This disproportionate decrease in Type II fiber CSA resulted in an increase $(p<0.05)$ in the percentage of total area occupied by the Type I fibers (Table 2). Figure 2 presents four light micrographs obtained from a control animal. Each section of the costal diaphragm was stained with a monoclonal antibody that reacts with a specific rat myosin heavy chain (MHC) type. 
TABLE 1. BODY AND MUSCLE WEIGHTS OF MECHANICALLY VENTILATED, SPONTANEOUSLY BREATHING, AND CONTROL ANIMALS

\begin{tabular}{lccc}
\hline & CON & SB & MV \\
\hline Initial body mass, g & $277.2+5.1$ & $307.4+8.7^{*}$ & $290.1+9.1$ \\
Final body mass, g & $277.2+5.1$ & $302.1+8.4^{*}$ & $289.4+8.9$ \\
Total DIA mass, mg & $1,056+16$ & $1,162+38^{*}$ & $981+11^{*+}$ \\
Total DIA mass/body mass ${ }^{\ddagger}, \mathrm{mg} / \mathrm{g}$ & $3.82+0.07$ & $3.85+0.06$ & $3.42+0.1^{*^{+}}$ \\
Costal DIA mass, mg & $699+12$ & $2.60+34^{*}$ & $648+7^{*+}$ \\
Costal DIA mass/body mass ${ }^{\ddagger}, \mathrm{mg} / \mathrm{g}$ & $2.53+0.05$ & $374+10$ & $2.26+0.07^{*+}$ \\
Crural DIA mass, mg & $357+8$ & $1.24+0.05$ & $334+12^{+}$ \\
Crural DIA mass/body mass, ${ }^{\ddagger} \mathrm{mg} / \mathrm{g}$ & $1.29+0.3$ & $129.8+5$ & $1.16+0.05$ \\
Soleus mass, mg & $131.8+8$ & $0.43+0.012$ & $140.7+6$ \\
Soleus mass/body mass ${ }^{\ddagger}, \mathrm{mg} / \mathrm{g}$ & $0.47+0.022$ & $0.49+0.016$ \\
\hline
\end{tabular}

Definition of abbreviations: $\mathrm{CON}=$ control animals; $\mathrm{DIA}=$ diaphragm; $\mathrm{MV}=$ mechanical ventilation animals; $\mathrm{SB}=\mathrm{spontaneously}$ breathing animals.

Values represent means + SEM.

* Significantly different from control group, $p<0.05$.

+ Significantly different from spontaneously breathing group, $\mathrm{p}<0.05$.

‡ Mass values expressed as milligrams per gram were normalized to postexperiment body mass values.

\section{Measurement of Myofibrillar Protein Concentration and Water Content}

Table 3 contains measurements of diaphragmatic protein concentrations and water content. Note that the protein and water content did not differ between the control and spontaneously breathing animals. In contrast, compared with control animals, 18 hours of MV resulted in significant reductions $(\mathrm{p}<0.05)$ in all measures of diaphragmatic protein. The concentrations of both myofibrillar protein and soluble protein decreased $(\mathrm{p}<$ $0.05)$ by about $10 \%$, resulting in a significant decrease $(\mathrm{p}<0.05)$ in the total protein concentration. Consistent with the loss of diaphragmatic mass was the reduction in total and myofibrillar protein content, reflecting an absolute loss of protein from the diaphragm. In addition, MV resulted in a mean increase (about $4 \%$ ) in muscle water content. Note that this increase in diaphragmatic water content was observed in every experimental animal.

\section{MV, Protease Activity, and Proteolysis}

Our results clearly indicate that both total calpain-like activity and the activity of the $20 \mathrm{~S}$ proteasome are elevated by 18 hours of MV (Figure 3). Indeed, 18 hours of MV elevated calpainlike activity by about $128 \%$. Similarly, MV resulted in a $470 \%$ increase in the activity of the $20 \mathrm{~S}$ proteasome.

Whole muscle breakdown was determined by measuring the rate of tyrosine release from in vitro diaphragm strips. Compared with control animals, the rate of diaphragmatic catabolism was accelerated after 18 hours of MV as indicated by a $46 \%$ increase $(\mathrm{p}<0.05)$ in tyrosine release (Figure 4$)$. Note that the rate of tyrosine release was not measured from diaphragms obtained

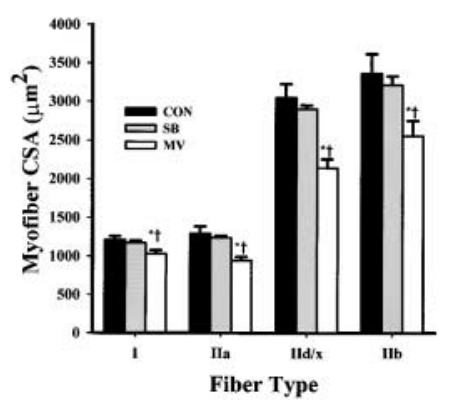

Figure 1. Diaphragmatic muscle fiber cross-sectional area (CSA) from control animals (CON),

spontaneously breathing animals $(S B)$, and animals exposed to 18 hours of mechanical ventilation $(M V)$. Values represent means + SEM ( $n=4$ /group). *Significantly less $(p<0.05)$ than control animals; 'significantly less $(p<0.05)$ than spontaneously breathing animals. from the anesthetized, spontaneously breathing animals. The rationale for this exclusion was that the spontaneously breathing animals did not experience diaphragmatic atrophy, as indicated by the finding that fiber CSA, muscle wet weight, and muscle protein content did not differ $(\mathrm{p}>0.05)$ from the acutely anesthetized (control) animals.

Addition of the calpain blocker E-64d resulted in a significant decrease in diaphragmatic proteolysis in both the control and MV animals (Figure 4). Further, inhibition of proteasome activity by the addition of lactacystin resulted in a significant decline in the rate of diaphragmatic proteolysis in both control and MV animals. Collectively, these results confirm that MV-induced diaphragmatic proteolysis is mediated by both the calpain and proteasome systems.

\section{Measurement of Diaphragm Oxidative Injury}

Two measures of oxidative stress were assessed to determine whether prolonged MV is associated with an increase in diaphragmatic oxidative damage. Compared with control animals, protein oxidation, as measured by protein carbonyl levels, and lipid peroxidation, as measured by 8 -isoprostane concentration, were significantly increased by 18 hours of MV, 44 and $53 \%$, respectively (Figures 5A and 5B). In contrast, no differences existed in protein carbonyl levels between control and spontaneously breathing animals. Note that 8 -isoprostane was not measured from diaphragms obtained from the anesthetized, spontaneously breathing animals because the spontaneously breathing animals did not experience diaphragmatic atrophy (as mentioned above) and the protein carbonyl content did not differ from that of the acutely anesthetized (control) animals.
TABLE 2. PERCENTAGE OF TOTAL CROSS-SECTIONAL AREA OCCUPIED BY EACH DIAPHRAGMATIC FIBER TYPE

\begin{tabular}{lcccc}
\hline Group & Type I & Type Ila & Type IId/x & Type IIb \\
\hline CON & $24.6+1.1$ & $22.7+1.5$ & $42.9+1.9$ & $9.8+1.3$ \\
SB & $25.1+1.5$ & $25.5+1.1$ & $41.9+2.1$ & $7.4+1.0$ \\
MV & $29.5+0.5^{*^{+}}$ & $24.3+2.4$ & $38.1+2.1$ & $8.1+0.3$
\end{tabular}

Definition of abbreviations: $\mathrm{CON}=$ control animals; $\mathrm{MV}=$ mechanical ventilation animals; SB = spontaneously breathing animals.

Values represent mean percentages + SEM.

* Significantly different from control group, $\mathrm{p}<0.05$.

+ Significantly different from spontaneously breathing group, $\mathrm{p}<0.05$. 

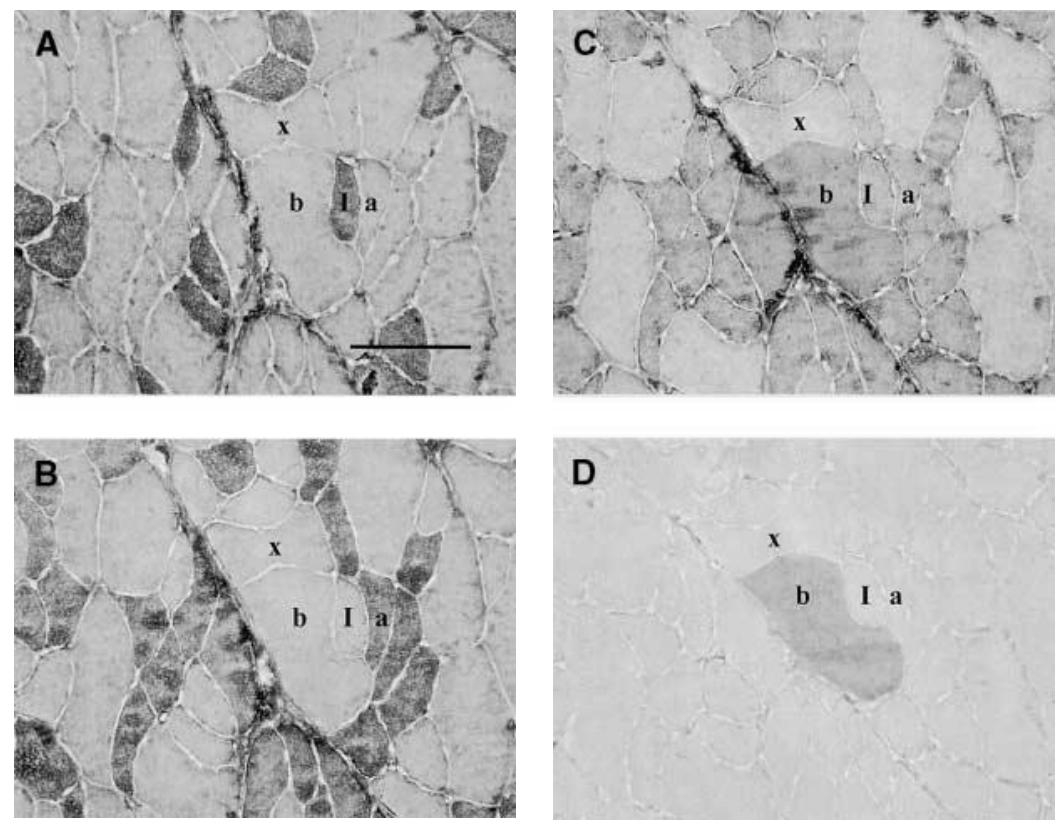

Figure 2. Photomicrographs illustrating the use of immunohistochemistry to identify costal diaphragm fiber types and determine fiber CSA in a control rat. Serial cross-sections of diaphragm muscle were immunohistochemically stained with $(A)$ anti-Type I MHC (BA-D5), (B) anti-Type Ila $\mathrm{MHC}$ (SC-71), (C) anti-Type Ilx MHC (BF-35), or (D) anti-Type Ilb MHC (BF-F3). Type I MHC, I; Type Ila MHC, $a$; Type IIx MHC, $x$; Type Ilb MHC, b. Scale bar in $(A)$ represents $100 \mu \mathrm{m}$.

\section{DISCUSSION}

\section{Overvlew of Major Flndings}

These are the first experiments to examine the mechanism(s) responsible for MV-induced diaphragmatic atrophy. Our data support the supposition that MV is associated with increased proteolysis and atrophy of all diaphragmatic fiber types. Further, our data uphold the hypothesis that MV-induced proteolysis is associated with increased diaphragmatic calpain and $20 \mathrm{~S}$ proteasome activity along with an increase in diaphragmatic oxidative stress. A detailed discussion of these data and the interpretations related to our hypotheses follow.

\section{MV-Induced Dlaphragmatlc Atrophy}

Importantly, our results indicate that no differences existed in any of our diaphragmatic measurements (e.g., diaphragmatic mass, fiber CSA, protein content) between the control (acute anesthesia) and the spontaneously breathing animals (18 hours of anesthesia). These observations reveal that sodium pentobarbital anesthesia is not responsible for the diaphragmatic proteolysis and atrophy associated with controlled MV.

Consistent with a previous report (3), our data indicate that controlled MV resulted in significant atrophy within the costal region of the rat diaphragm. Interestingly, the observed atrophy was unique to the diaphragm, as there was no loss of total body mass and no reduction in the mass of the soleus muscle. These results indicate that the removal of mechanical activity from the

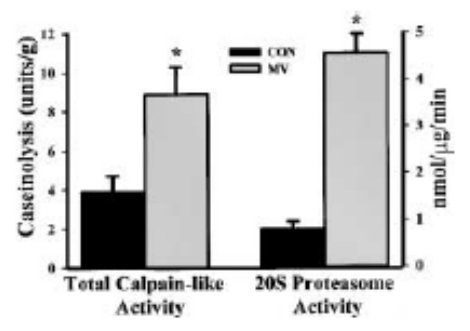

Figure 3. Effect of mechanical ventilation on total calpainlike activity and $20 \mathrm{~S}$ proteasome activity in the diaphragm of control $(\mathrm{CON})$ and mechanical ventilation (MV) animals. Values represent means \pm SEM $(n=4 /$ group). *Significantly greater than control, $\mathrm{p}<0.05$. chronically active diaphragm via controlled MV leads to rapid muscle atrophy.

We identified diaphragmatic MHC types by a multiple monoclonal antibody immunohistochemical approach and measured fiber CSA via computerized image analysis. Our results support the hypothesis that 18 hours of controlled MV promotes a significant reduction in the CSA of all four diaphragmatic MHC types. Interestingly, Type II fibers atrophied to a greater extent than Type I fibers. The fact that Type II fibers undergo the greatest degree of atrophy in the diaphragm during MV differs from investigations of locomotor muscle during periods of muscle disuse. Indeed, reports using the hindlimb suspension model of unloading rat skeletal muscles indicate that whereas Type II fibers suffer muscle atrophy during disuse, Type I fibers are preferentially susceptible to muscle atrophy during muscle unloading (reviewed in Roy and coworkers [5]).

The observation that MV results in diaphragmatic atrophy in all muscle fiber types also differs from several studies investigating diaphragmatic adaptation to inactivity. Specifically, two previous experiments reveal that 14 days of diaphragmatic inactivity, due to either bilateral denervation or tetrodotoxin blockade of nerve impulses, results in a selective atrophy of Type IIb and IIx fibers and a transient hypertrophy of both Type I and IIa fibers $(6,8)$. The biological mechanism(s) responsible for this variation in the diaphragmatic response to differing models of inactivity are unclear but could be related to differences in passive movement of the diaphragm between these experimental paradigms. For example, it has been shown that during controlled $\mathrm{MV}$, the right and left hemidiaphragms undergo passive shortening during mechanical expansion of the lungs (28). In contrast, bilateral inactivity of the diaphragm, due to either nerve blockage or denervation, results in passive stretching of the inactivated diaphragm region during inspiration (7). This is significant because it has been postulated that the transient hypertrophy of Type I and IIa fibers in the rat diaphragm during bilateral denervation is due to increased protein synthesis induced by the passive stretch of the muscle during breathing $(29,30)$. Although this is an attractive explanation for these experimental differences, the direct effect of either passive stretch or passive 


\begin{tabular}{lrrr}
\hline & \multicolumn{1}{c}{ CON } & \multicolumn{1}{c}{ SB } & MV \\
\hline Total protein concentration, $\mathrm{mg} / \mathrm{g}$ & $237.2+5.1$ & $239.6+4.7$ & $213.2+9.4^{*+}$ \\
Total protein content, ${ }^{+} \mathrm{mg}$ & $165.6+3.6$ & $163.7+3.2$ & $138.2+6.2^{*^{+}}$ \\
Myofibrillar protein concentration, $\mathrm{mg} / \mathrm{g}$ & $128.2+2.5$ & $136.1+2.3$ & $115.3+5.2^{*^{+}}$ \\
Myofibrillar protein content, ${ }^{5} \mathrm{mg}$ & $89.5+1.6$ & $93.1+1.5$ & $74.8+3.4^{*^{+}}$ \\
Soluble protein concentration, ${ }^{1} \mathrm{mg} / \mathrm{g}$ & $108.9+2.8$ & $103.5+4.5$ & $97.8+4.4^{*}$ \\
Soluble protein content, ${ }^{1} \mathrm{mg}$ & $76.1+1.9$ & $70.7+3.1$ & $63.4+2.3^{*}$ \\
Water content, $\%$ & $74.3+0.4$ & $74.4+1.1$ & $77.4+0.5^{*+}$ \\
\hline
\end{tabular}

Definition of abbreviations: $\mathrm{CON}=$ control animals; $\mathrm{g}=$ gram wet weight; $\mathrm{MV}=$ mechanical ventilation animals; $\mathrm{SB}=$ spontaneously breathing animals.

Values represent means + SEM. All measurements were made on the costal portion of the diaphragm.

* Significantly different from control group, $\mathrm{p}<0.05$.

${ }^{+}$Significantly different from spontaneously breathing group, $\mathrm{p}<0.05$.

₹ Total protein content equals costal diaphragm mass $(\mathrm{g})$ times costal protein concentration.

$\S$ Total myofibrillar protein content equals costal diaphragm mass (g) times costal myofibrillar protein concentration.

${ }^{1}$ Soluble protein content equals costal diaphragm mass $(\mathrm{g})$ times costal soluble protein concentration.

shortening on diaphragmatic adaptation to inactivity remains unknown; this is an interesting area for future research.

Concomitant with the MV-induced decrease in muscle fiber CSA was the loss of diaphragmatic protein. Compared with control diaphragms, 18 hours of MV was associated with a reduction in both diaphragmatic myofibrillar and soluble protein; this loss of protein was observed in both protein concentration and total protein content. In addition to the loss of protein, MV resulted in a $4 \%$ increase in diaphragmatic water content. The increase in muscular water content would explain the decrease in muscle protein concentration and is consistent with the increased water content that occurs in conjunction with muscular injury (31). Nonetheless, whether MV results in diaphragmatic injury cannot be determined from our current data.

Functionally, this MV-induced reduction in protein concentration could contribute to the observed reduction in diaphragmatic maximal specific force production after MV $(3,4)$. Theoretically, the reduction in myofibrillar protein concentration would result in fewer myosin cross-bridges per cross-sectional area of muscle and therefore less specific force generation. This is a testable hypothesis and is worthy of study.

\section{Mechanisms for MV-induced Atrophy}

A reduction in skeletal muscle protein can occur as a result of a decreased rate of protein synthesis, an increased rate of protein degradation, or both. Previous studies investigating locomotor skeletal muscle atrophy during disuse indicate that this type of atrophy is due to both a reduced rate of protein synthesis and an increased rate of protein breakdown. Indeed, within hours of the onset of muscle disuse (i.e., hindlimb unweighting) the rate of muscle protein synthesis can decline by as much as $50 \%$

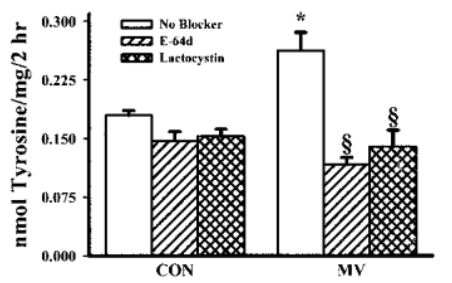

Figure 4. Effect of mechanical ventilation on whole muscle protein catabolism as measured by the rate of tyrosine released from in vitro diaphragm strips per wet weight of muscle in 2 hours, and the impact of specific calpain (E64d) and proteasome (lactacystin) inhibitors on the rates of diaphragmatic proteolysis. Control animals, CON; mechanical ventilation animals, $M V$. Values represent means + SEM ( $n=4$ /group). *Significantly greater than control value, $p<0.05$. ${ }^{5}$ Significantly less than mechanical ventilation tyrosine release, under no blocker condition, $\mathrm{p}<0.05$.
(32). However, because the rate of protein synthesis was not measured in the present study, the relative contribution of decreased protein synthesis to MV-induced atrophy of the diaphragm cannot be quantified. Nonetheless, our results support the hypothesis that protein degradation is significantly accelerated after 18 hours of MV and that MV-induced diaphragmatic atrophy is due, in part, to an increased rate of protein degradation (Figure 4). To clarify the role that specific proteases play in this MV-induced proteolysis, we used complementary but differing experimental approaches that included measurements of in vitro protein breakdown with and without proteolytic inhibitors along with measurement of calpain and $20 \mathrm{~S}$ proteasome activities. Our results indicate that both the calpain and $20 \mathrm{~S}$ proteasome systems contribute to MV-induced diaphragmatic proteolysis. Indeed, compared with control animals, both $20 \mathrm{~S}$ proteasome and calpain activities were elevated in diaphragms of MV animals (Figure 3). Furthermore, we observed a significant
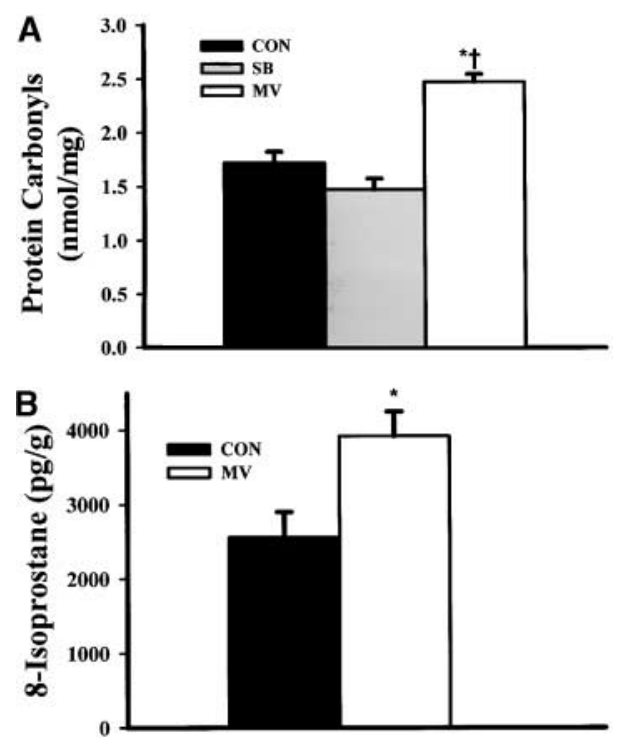

Figure 5. Effect of mechanical ventilation on two measures of oxidative stress, protein carbonyl concentration $(A)$, and total 8-isoprostane concentration in $\mathrm{pg} / \mathrm{g}$ wet weight of muscle $(B)$. Control animals, $C O N$; spontaneously breathing animals, $S B$; mechanical ventilation animals, $M V$. Values represent means +SEM ( $\mathrm{n}=8 /$ group). *Significantly greater than control value, $\mathrm{p}<0.05 ;{ }^{+}$significantly greater than spontaneously breathing animal value, $\mathrm{p}<0.05$. 
reduction in the rate of tyrosine release during in vitro incubation of diaphragm strips from MV animals after the addition of either a proteasome inhibitor (lactacystin) or an inhibitor of both calpain and lysosomal proteases (E-64d). Collectively, these results

provide strong support for the notion that both the calpain and proteasome systems contribute to MV-induced diaphragmatic proteolysis. Although it is possible that lysosomal proteases also contribute to MV-induced proteolysis in the diaphragm, previous experiments suggest that the contribution of cathepsins to muscle disuse atrophy is quantitatively small (10).

Finally, our results also support our hypothesis that MV results in an increase in diaphragmatic oxidative stress as indicated by the increase in the diaphragmatic content of both protein carbonyls and total 8-isoprostane. In the context of MV-induced diaphragmatic atrophy, an increase in protein oxidation is important because moderately oxidized proteins are more sensitive to proteolytic attack by proteases (11-14). Therefore, oxidative modification of proteins could accelerate protein degradation in the diaphragm during MV. Further, the ubiquitin-proteasome pathway is the proteolytic pathway implicated in the degradation of actin and myosin in muscle $(10,33)$, and this pathway is upregulated during periods of oxidative stress (34-36). An oxidative stress-mediated upregulation of the ubiquitin-proteasome pathway would lead to an increase in protein degradation and thus atrophy. Therefore, we postulate that oxidative stress may play an integral role in MV-induced atrophy of the diaphragm.

\section{Conclusion}

Our findings clearly demonstrate that short-term controlled MV leads to rapid diaphragmatic atrophy. Indeed, after 18 hours of $\mathrm{MV}$, diaphragmatic protein content and mass were significantly reduced and this was reflected by a decrease in the CSA of all four diaphragmatic MHC types. Further, oxidative stress was increased and total protein degradation was accelerated after MV. The MV-induced increase in diaphragmatic proteolysis was associated with an increase in both calpain and 20S proteasome activities. Future experiments should be directed toward understanding signaling pathways responsible for both the sequential activation of proteolytic systems and the production of oxidants within the diaphragm during periods of unloading due to MV.

\section{References}

1. Lemaire F. Difficult weaning. Intensive Care Med 1993:19:S69_S73.

2. Tobin MJ, Laghi F, Jubran A. Respiratory muscle dysfunction in mechanically-ventilated patients. Mol Cell Biochem 1998;179:87-98.

3. Le Bourdelles G, Viires N, Boczkowski J, Seta N, Pavlovic D, Aubier M. Effects of mechanical ventilation on diaphragmatic contractile properties in rats. Am J Respir Crit Care Med 1994;149:1539-1544.

4. Powers SK, Shanely RA, Coombes JS, Koesterer TJ, McKenzie M, Van Gammeren D, Cicale M, Dodd SL. Mechanical ventilation results in progressive contractile dysfunction in the diaphragm. $J$ Appl Physiol 2002;92:1851-1858.

5. Roy RR, Baldwin KM, Edgerton VR. Response of the neuromuscular unit to spaceflight: what has been learned from the rat model. Exerc Sport Sci Rev 1996,24:399-425.

6. Miyata H, Zhan WZ, Prakash YS, Sieck GC. Myoneural interactions affect diaphragm muscle adaptations to inactivity. J Appl Physiol 1995; 79:1640-1649.

7. Zhan WZ, Sieck GC. Adaptations of diaphragm and medial gastrocnemius muscles to inactivity. $J$ Appl Physiol 1992;72:1445-1453.

8. Zhan WZ, Miyata H, Prakash YS, Sieck GC. Metabolic and phenotypic adaptations of diaphragm muscle fibers with inactivation. $J$ Appl Physiol 1997:82:1145-1153.

9. Kondo H, Nakagaki I, Sasaki S, Hori S, Itokawa Y. Mechanism of oxidative stress in skeletal muscle atrophied by immobilization. Am J Physiol 1993:265:E839-E844.

10. Taillandier D, Aurousseau E, Meynial-Denis D, Bechet D, Ferrara M, Cottin P, Ducastaing A, Bigard X, Guezennec CY, Schmid HP. Coordinate activation of lysosomal, $\mathrm{Ca}^{2+}$-activated and ATP-ubiquitin- dependent proteinases in the unweighted rat soleus muscle. Biochem $J 1996 ; 316: 65-72$.

11. Nagasawa T, Hatayama T, Watanabe Y, Tanaka M, Niisato Y, Kitts DD Free radical-mediated effects on skeletal muscle protein in rats treated with Fe-nitrilotriacetate. Biochem Biophys Res Commun 1997;231:3741.

12. Davies KJ, Goldberg AL. Proteins damaged by oxygen radicals are rapidly degraded in extracts of red blood cells. J Biol Chem 1987;262:82278234

13. Levine RL, Oliver CN, Fulks RM, Stadtman ER. Turnover of bacterial glutamine synthetase: oxidative inactivation precedes proteolysis. Proc Natl Acad Sci USA 1981;78:2120-2124.

14. Dean RT, Fu S, Stocker R, Davies MJ. Biochemistry and pathology of radical-mediated protein oxidation. Biochem $J$ 1997;324:1-18.

15. Tao HY, Farkas GA. Predictability of ventilatory muscle optimal length based on excised dimensions. J Appl Physiol 1992;72:2024-2028.

16. Solaro RJ, Pang DC, Briggs FN. The purification of cardiac myofibrils with Triton X-100. Biochim Biophys Acta 1971;245:259-262.

17. Watters C. A one-step biuret assay for protein in the presence of detergent. Anal Biochem 1978;88:695-698.

18. Tischler ME, Desautels M, Goldberg AL. Does leucine, leucyl-tRNA, or some metabolite of leucine regulate protein synthesis and degradation in skeletal and cardiac muscle? J Biol Chem 1982;257:1613-1621.

19. Waalkes T, Undenfriend S. A fluorometric method for the estimation of tyrosine in plasma and tissues. J Lab Clin Med 1957;50:733-736.

20. Temparis S, Asensi M, Taillandier D, Aurousseau E, Larbaud D, Obled A, Bechet D, Ferrara M, Estrela JM, Attaix D. Increased ATP-ubiquitin-dependent proteolysis in skeletal muscles of tumor-bearing rats. Cancer Res 1994;54:5568-5573.

21. Tiao G, Fagan JM, Samuels N, James JH, Hudson K, Lieberman M, Fischer JE, Hasselgren PO. Sepsis stimulates nonlysosomal, energydependent proteolysis and increases ubiquitin mRNA levels in rat skeletal muscle. J Clin Invest 1994;94:2255-2264.

22. Craiu A, Gaczynska M, Akopian T, Gramm CF, Fenteany G, Goldberg AL, Rock KL. Lactacystin and clasto-lactacystin J3-lactone modify multiple proteasome J3-subunits and inhibit intracellular protein degradation and major histocompatibility complex class I antigen presentation. J Biol Chem 1997;272:13437-13445.

23. Lee DH, Goldberg AL. Proteasome inhibitors: valuable new tools for cell biologists. Trends Cell Biol 1998;8:397-403.

24. Raj DA, Booker TS, Belcastro AN. Striated muscle calcium-stimulated cysteine protease (calpain-like) activity promotes myeloperoxidase activity with exercise. Pflugers Arch 1998;435:804-809.

25. Belcastro AN. Skeletal muscle calcium-activated neutral protease (calpain) with exercise. J Appl Physiol 1993;74:1381-1386

26. Stein RL, Melandri F, Dick L. Kinetic characterization of the chymotryptic activity of the 20 S proteasome. Biochemistry 1996:35:3899-3908.

27. Reznick AZ, Packer L. Oxidative damage to proteins: spectrophotometric method for carbonyl assay. Methods Enzymol 1994:233:357-363.

28. Froese AB, Bryan AC. Effects of anesthesia and paralysis on diaphragmatic mechanics in man. Anesthesiology 1974;41:242-255.

29. Hopkins D, Manchester KL, Gregory M. Histochemical and biochemical characteristics of the transient hypertrophy of the denervated rat hemidiaphragm. Exp Neurol 1983;81:279-293.

30. Yellin $\mathrm{H}$. Changes in fiber types of the hypertrophying denervated hemidiaphragm. Exp Neurol 1974;42:412-428.

31. Komulainen J, Kytola J, Vihko V. Running-induced muscle injury and myocellular enzyme release in rats. J Appl Physiol 1994;77:2299-2304.

32. Thomason DB, Herrick RE, Surdyka D, Baldwin KM. Time course of soleus muscle myosin expression during hindlimb suspension and recovery. J Appl Physiol 1987;63:130-137.

33. Furuno K, Goodman MN, Goldberg AL. Role of different proteolytic systems in the degradation of muscle proteins during denervation atrophy. J Biol Chem 1990;265:8550-8557.

34. Shang F, Gong X. Taylor A. Activity of ubiquitin-dependent pathway in response to oxidative stress: ubiquitin-activating enzyme is transiently up-regulated. J Biol Chem 1997;272:23086-23093.

35. Scrofano MM, Shang F, Nowell TRJ, Gong X, Smith DE, Kelliher M, Dunning J, Mura CV, Taylor A. Calorie restriction, stress and the ubiquitin-dependent pathway in mouse livers. Mech Ageing Dev 1998; 105:273-290.

36. Thevenod F, Friedmann JM. Cadmium-mediated oxidative stress in kidney proximal tubule cells induces degradation of $\mathrm{Na}^{+} / \mathrm{K}^{+}$-ATPase through proteasomal and endo-/lysosomal proteolytic pathways. 